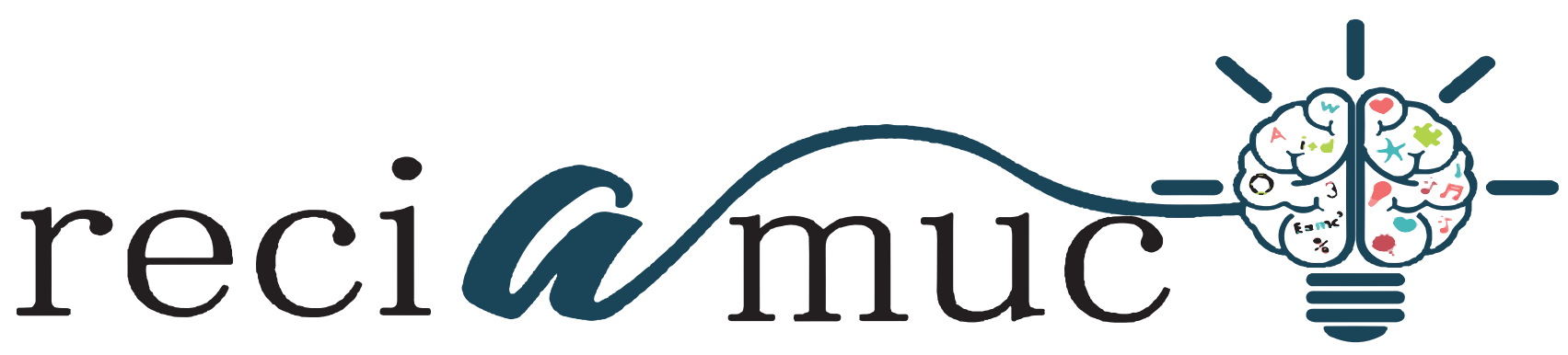

DOI: $10.26820 /$ reciamuc/4.(3).julio.2020.58-68

URL: https://reciamuc.com/index.php/RECIAMUC/article/view/499

EDITORIAL: Saberes del Conocimiento

REVISTA: RECIAMUC

ISSN: 2588-0748

TIPO DE INVESTIGACIÓN: Artículo de Revisión

Código UNESCO: 32 Ciencias Médicas; 3201 Ciencias Clínicas

PAGINAS: $58-68$

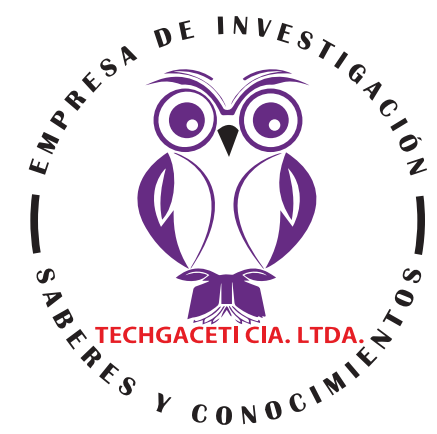

\title{
Covid 19, el embarazo, el parto y la lactancia materna
}

Covid 19, pregnancy, childbirth, and breastfeeding

Covid 19, gravidez, parto e amamentação

\section{Jorge Aleghyery Merchan Villamar'; Santo Eduardo Cedeño Cedeño²; Karina Erminia Rayo Caicedo ${ }^{3}$}

\author{
RECIBIDO: 20/05/2020 ACEPTADO: 19/07/2020 PUBLICADO: 30/07/2020
}

1. Especialista en Ginecología y Obstetricia; Doctor en Medicina y Cirugía; Investigador Independiente; Guayaquil, Ecuador; drjorgemechan3@gmail.com; (iD https://orcid.org/0000-0001-9468-7525

2. Doctor en Medicina; Investigador Independiente; Guayaquil, Ecuador; eduardocedenoc@hotmail.com; (iD https://orcid. org/0000-0003-1069-9583

3. Médico; Investigador Independiente; Guayaquil, Ecuador; karinarayo@hotmail.com; (D) https://orcid.org/0000-0003-1777$147 X$

\section{CORRESPONDENCIA}

Jorge Aleghyery Merchan Villamar

drjorgemechan3@gmail.com

Guayaquil, Ecuador

○ RECIAMUC; Editorial Saberes del Conocimiento, 2020 


\section{RESUMEN}

En diciembre de 2019 fueron identificaron en Wuhan (China) una serie de casos de neumonía originados por un nuevo coronavirus, que cuenta con distintas denominaciones: 2019-nCoV según la OMS y SARS-CoV-2 según el Comité Internacional de Taxonomía de Virus. La enfermedad causada se denomina Covid 19 y una de sus características más relevantes es su rápida diseminación a nivel mundial. Produce cuadros de infección leve en la mayoría de los casos, no obstante, el porcentaje de pacientes que progresan en severidad es considerable, los cuales requieren de un manejo en cuidados intensivos, aproximadamente entre el 5 y el 36\%, y del total de estos casos críticos alrededor de un $50 \%$ fallece por esta causa. La presente revisión permite plasmar todo lo relativo al Covid 19 en el periodo del embarazo, durante el parto y después de este, destacando las consideraciones para el cuidado del recién nacido y la lactancia materna. El modelo de investigación es una revisión de tipo documental bibliográfico. Las medidas de prevención para la embarazada sana evitar el contagio del Covid 19 son básicamente las mismas que para la población en general. Existe escasa evidencia científica disponible, sin embargo, se conoce que las embarazadas corren los mismos riesgos de enfermar gravemente que el resto de la población, asimismo no es concluyente que exista transmisión vertical del virus, así como tampoco se ha encontrado el virus en la leche materna. La evidencia disponible permite elaborar los diferentes protocolos y recomendaciones para el manejo del virus y la enfermedad. Es fundamental la comunicación entre la embarazada contagiada y el personal de salud, a los fines de proporcionar el mayor cuidado posible durante el embarazo, el parto y el puerperio, y tomar las decisiones que más le beneficie a la madre y al recién nacido, evitando la propagación del virus.

Palabras clave: Covid 19, Embarazo, Parto, Lactancia, Materna.

\section{ABSTRACT}

In December 2019, a series of cases of pneumonia caused by a new coronavirus were identified in Wuhan (China), which has different names: 2019-nCoV according to the WHO and SARS-CoV-2 according to the International Committee on Virus Taxonomy. The disease caused is called Covid 19 and one of its most relevant characteristics is its rapid spread worldwide. It produces symptoms of mild infection in most cases, however, the percentage of patients that progress in severity is considerable, which require intensive care management, approximately between 5 and $36 \%$, and of the total of these critical cases around 50\% die from this cause. The present review allows us to capture everything related to Covid 19 in the period of pregnancy, during and after delivery, highlighting the considerations for newborn care and breastfeeding. The research model is a bibliographic documentary type review. The preventive measures for the healthy pregnant woman to avoid the spread of Covid 19 are basically the same as for the general population. There is little scientific evidence available, however, it is known that pregnant women run the same risks of becoming seriously ill as the rest of the population, it is also inconclusive that there is vertical transmission of the virus, as well as the virus has not been found in milk maternal. The available evidence allows the elaboration of the different protocols and recommendations for the management of the virus and the disease. Communication between the infected pregnant woman and health personnel is essential, in order to provide the greatest possible care during pregnancy, childbirth and the puerperium, and to make the decisions that benefit the mother and the newborn the most, avoiding the spread of the virus.

Keywords: Covid 19, Pregnancy, Childbirth, Lactation, Maternal.

\section{RESUMO}

Em dezembro de 2019, uma série de casos de pneumonia causada por um novo coronavírus foi identificada em Wuhan (China), que tem nomes diferentes: 2019-nCoV de acordo com a OMS e SARS-CoV-2 de acordo com o Comitê Internacional de Taxonomia de Vírus. A doença causada é chamada Covid 19 e uma de suas características mais relevantes é sua rápida disseminação em todo o mundo. Produz sintomas de infecção leve na maioria dos casos, no entanto, a porcentagem de pacientes que progride em gravidade é considerável, o que requer tratamento intensivo, aproximadamente entre 5 e $36 \%$, e do total desses casos críticos, cerca de $50 \%$ morrem por causa disso. causa. A presente revisão nos permite capturar tudo relacionado ao Covid 19 no período da gravidez, durante e após o parto, destacando as considerações sobre cuidados com o recém-nascido e amamentação. O modelo de pesquisa é uma revisão bibliográfica do tipo documental. As medidas preventivas para a gestante saudável evitar a disseminação do Covid 19 são basicamente as mesmas da população em geral. Há poucas evidências científicas disponíveis, no entanto, sabe-se que as mulheres grávidas correm os mesmos riscos de adoecer gravemente que o restante da população, também é inconclusivo que haja transmissão vertical do vírus, assim como o vírus não foi encontrado no leite materno. As evidências disponíveis permitem a elaboração dos diferentes protocolos e recomendações para o manejo do vírus e da doença. A comunicação entre a gestante infectada e a equipe de saúde é essencial, a fim de proporcionar o melhor atendimento possível durante a gravidez, o parto e o puerpério, e tomar as decisões que mais beneficiam a mãe e o recém-nascido, evitando a propagação do vírus.

Palavras-chave: Covid 19, Gravidez, Parto, Aleitamento Materno. 


\section{Introducción}

En diciembre de 2019 fueron identificaron en Wuhan (China) una serie de casos de neumonía originados por un nuevo coronavirus. "Este nuevo coronavirus tiene distintas denominaciones: 2019-nCoV según la OMS y SARS-CoV-2 según el Comité Internacional de Taxonomía de Virus. La enfermedad que lo causa se ha denominado 2019-nCoV1". Para el 7 de enero de 2020, se anunció oficialmente el nuevo coronavirus por las autoridades chinas como el agente causal de dichas infecciones. (Palacios Cruz, Santos, Velázquez, \& León, 2020)

En fecha 30 de enero del 2020, el Director General de la OMS, declaró al Covid-19 como una emergencia de salud pública, relevante a nivel mundial, de conformidad con el Reglamento Sanitario Internacional (2005). En la Región de las Américas, el primer caso confirmado se registró en los Estados Unidos, en fecha 20 de enero del 2020. Brasil reportó el primer caso de América Latina y el Caribe, en fecha 26 de febrero del 2020. En la actualidad el Covid 19 se ha propagado a todos los 54 países y territorios de la Región de las Américas. Para el 4 de mayo del 2020 la Organización Mundial de la Salud registró un total de 1.477.448 casos confirmados, un total de 86.342 muertos y el virus presente en los 54 países, zonas y territorios contados con fines epidemiológicos. (Organización Panamericana de la Salud, 2020)

Borre, Santacruz, González, Anichiarico, \& Rubio (2020) refieren que una de las características más relevantes de este virus es su rápida diseminación a nivel mundial. Produce cuadros de infección leve en la mayoría de los casos, no obstante, el porcentaje de pacientes que progresan en severidad es considerable, los cuales requieren de un manejo en cuidados intensivos, aproximadamente entre el 5 y el 36\%, y del total de estos casos críticos alrededor de un 50\% fallece por esta causa. (p. 99)
Existe un camino muy largo por recorrer en el estudio de este nuevo virus y su enfermedad, sobre todo en la población de embarazadas y recién nacidos, donde los estudios son escasos, sin embargo, los existentes sirven como base para establecer algunas recomendaciones y procedimientos, tal es el caso del estudio de Chen $\mathrm{H}$. et al. 2020, citado por Gutiérrez, Zelaya, Castellanos, \& Domínguez (2020), realizado en China en mujeres embarazadas con Covid-19. En este estudio se observó que los partos prematuros y sufrimiento fetal descritos no estuvieron relacionados a neumonía por coronavirus. No obstante, es importante considerar que los resultados obstétricos adversos más comunes relacionados con la neumonía por todas las causas incluyen: "Ruptura prematura de membranas (RPM), trabajo de parto prematuro, muerte intrauterina, restricción de crecimiento intrauterino y muerte neonatal, y que dicho resultado se tuvo con los coronavirus responsables de SARS y MERS". (p. 2)

Por otra parte, Pérez et al. (2020) en base a revisiones de evidencia disponible con relación al embarazo y el covid 19, se estableció que las mujeres embarazadas no son más gravemente afectadas que la población general, a pesar de ello, es necesario comparar con mujeres no embarazadas, de edad similar y no compararlas con el total de la población afectada. En cuanto a la posibilidad de transmisión intrauterina o perinatal, igualmente es desconocida, de los estudios revisados la mayoría de la población embarazada contrajo el virus en el tercer trimestre, razón por la que se desconocen los efectos del virus en etapas tempranas del embarazo. Con respecto a la lactancia materna, a pesar de que los datos son limitados, en estudios comparativos con las epidemias anteriores y SARS-CoV-2 no se logró determinar la transmisión por medio de la leche materna. (p. S7, S8)

Son muchos los interrogantes que se presentan con el Covid 19 en las embarazadas, durante el período del embarazo, el parto 
y el puerperio, además de todo lo concerniente con el recién nacido, dada la escasa evidencia científica y la novedad de la enfermedad, resulta fundamental compendiar las más recientes recomendaciones y mantenerse actualizado en todo lo concerniente a este tema.

El presente artículo se proporciona como un recurso para profesionales de la salud y público en general, fundamentando los conceptos en una combinación de información disponible (evidencia científica), buenas prácticas derivada de la evidencia disponible y opiniones de expertos en la materia, con el propósito de contribuir a la salud pública mundial. Su objetivo fundamental consiste en plasmar todo lo relativo al Covid 19 en el periodo del embarazo, durante el parto y después de este, destacando las consideraciones para el cuidado del recién nacido y la lactancia materna. Para ello se abordaron los siguientes subtítulos: la prevención de la embarazada ante el Covid 19, evidencia disponible sobre los efectos del Covid 19 en el embarazo, parto y el puerperio, control materno - fetal de la embarazada con Covid 19, trabajo de parto y nacimiento y, puerperio y recién nacido: el contacto con el recién nacido y la lactancia materna en la madre con Covid 19.

\section{Materiales y métodos}

La presente investigación se llevó a cabo mediante una búsqueda con el propósito de recolectar y seleccionar el material bibliográfico digital que sirvió para revisar y compendiar el tema del Covid 19 y el embarazo, el parto y la lactancia materna. La clasificación de la investigación que se llevó a cabo como es de tipo documental o bibliográfica.

Para ubicar el material digitalizado se utilizaron las siguientes bases de datos y páginas web relacionadas con el área de la salud a nivel internacional: PubMed, SciELO, NBCl, ELSEVIER, páginas como la Organización Mundial de la Salud (OMS), Organización Panamericana de la Salud
(OPS), el Ministerio de Salud de Argentina, entre otras. Para la búsqueda se usaron los siguientes descriptores: "Covid 19 y embarazo", "Covid 19 en la embarazada y parto"; "Covid 19 y lactancia materna" y "covid 19 en embarazadas y evidencia científica". Los registros bibliográficos encontrados fueron filtrados en base a los criterios de idioma los cuales fueron español e inglés, relevancia del tema, con una correlación temática y actuales (fecha de publicación del presente años, de febrero a julio).

\section{Resultados}

\section{La prevención de la mujer embarazada ante el Covid 19}

El riesgo que implica estar embarazada y desarrollar más gravemente el Covid 19, aún no se ha comprobado ampliamente. En la actualidad se llevan a cabo múltiples investigaciones con la finalidad de comprobar los efectos y consecuencias del Covid 19 en las embarazadas, no obstante, es importante que este grupo de la población tome las precauciones necesarias para evitar el contagio.

Según recomendaciones preliminares que reflejan los conocimientos sobre la infección actuales basados en la evidencia disponible, buenas prácticas y recomendaciones de la OMS y expertos, la mujer embarazada puede evitar infectarse con Coronavirus (Covid 19), llevando a cabo lo siguiente:

- Lávate las manos con agua y jabón durante el tiempo que te tome cantar dos veces el "cumpleaños feliz", hazlo varias veces al día y antes y después de comer o ir al baño. También puedes usar gel con alcohol (por lo menos al 70\%)

- Cúbrete la boca y la nariz al toser o estornudar, con el codo flexionado o con una servilleta o pañuelo de papel; bota la servilleta inmediatamente en un contenedor con tapa o en una bolsa que luego amarras y lávate las manos con agua y jabón o un desinfectante de ma- 
nos a base de alcohol.

Evita el contacto al saludar. No saludes dando la mano, con besos o abrazos; utiliza otros gestos como por ejemplo señales con la mano, inclinar la cabeza o cualquier otro que te parezca divertido para tu familia y amigos y amigas.

- Evita tocarte la cara sin antes lavarte las manos, especialmente los ojos, nariz y boca.

- No te acerques a menos de un metro (aprox. dos pasos) a otras personas, sobre todo las que tienen síntomas como tos o fiebre.

- Quédate en casa. Evitar salir a menos quesea necesario; evita sitios con mucha gente.

- Limpia todas las superficies que tocas normalmente varias veces al día con agua y cloro (prepara un envase de 1 litro poniendo $900 \mathrm{ml}$ de agua y $100 \mathrm{ml}$ de cloro -el contenido de una taza de café pequeña) u otro desinfectante. Por ejemplo, la mesa donde comes, escritorios, barandas, interruptores de luz, celular, teclados de computadora.

- Si convives con alguna persona que está enferma o con sospecha de coronavirus, procura que otra persona se encargue de sus cuidados.

- Evita viajar a menos que sea indispensable.

- Lava y cocina bien los alimentos. Evita compartir vasos, platos y artículos de uso personal.

- Mantén bien ventilado los espacios de tu hogar. Si es posible, con puertas y ventanas abiertas.

- Evita concurrir a establecimientos de salud para prevenir contacto con personas posiblemente infectadas. Para tu control prenatal averigua a través de un familiar en el establecimiento de salud más cercano (consultorio popular, centro de diagnóstico y tratamiento, u hospital) o por teléfono las indicaciones actualizadas para cumplir con los controles médicos de rutina. (OPS, 2020)

\section{Evidencia disponible sobre los efectos del Covid 19 en el embarazo, Parto y el Puerperio}

En la actualidad el conocimiento disponible en lo que respecta al impacto de la COVID-19 en la población de embarazadas y en recién nacidos $(\mathrm{RN})$ es aún limitado, no obstante, la escasa evidencia disponible es muy importante por cuanto permite contemplar diversos escenarios y diseñar recomendaciones.

El Ministerio de Salud de Argentina (2020), compendia la evidencia disponible al 20 de Julio de 2020, sobre los efectos del covid 19 en el embarazo, parto y puerperio de la siguiente manera:

- La evidencia disponible al momento sobre el impacto de la infección por COVID-19 durante el embarazo, sugiere que los riesgos de enfermedad grave en la persona gestante parecen ser similares a los de la población no gestante.

- Los equipos de salud deben tener en cuenta que, en el marco de atención de personas gestantes durante la pandemia, es imprescindible cumplir con las recomendaciones de medidas de distanciamiento, lavado de manos frecuente y el uso adecuado de EPP indicado para cada situación. De esta forma puede reducirse la exposición de las/ los trabajadores de salud. En las áreas definidas como de circulación comunitaria, los servicios de obstetricia asistirán personas gestantes infectadas con COVID-19. Esta particularidad puede requerir acciones particulares en relación con el uso de EPP y medidas de aislamiento preventivo (ej: uso de EPP en salas de parto, modos de aislamiento durante la internación en servicios de 
obstetricia y neonatología).

- Los estudios disponibles a la fecha sobre embarazadas afectadas con COVID-19 no son concluyentes respecto a la transmisión vertical. Se han reportado casos aislados de transmisión vertical, pero tanto las muestras utilizadas como los métodos diagnósticos más adecuados aún no han sido validados. Tampoco se ha demostrado que exista una asociación entre COVID-19 materna y el parto prematuro.

- Los estudios realizados sobre RN con COVID-19 reportan enfermedad leve en la mayoría de los casos. El modo de parto no tiene influencia sobre el riesgo vinculado a COVID-19 para la madre o el RN.

- El contacto piel a piel inmediato en el momento del nacimiento no parece aumentar el riesgo de enfermedad para el $\mathrm{RN}$.

- Los beneficios de la lactancia materna superan los eventuales riesgos, aun en el caso de lactancia directa, siempre que se respeten los cuidados de contacto y aislamiento por gota.

- Los RN asintomáticos no requieren estudios virológicos de rutina, excepto en el contexto de programas de vigilancia epidemiológica o para definiciones vinculadas al aislamiento preventivo en unidades de cuidado neonatal, en el caso que no fueran definidos como contactos estrechos. (p. 1, 2)

\section{Control materno - fetal de la embarazada con Covid 19}

González de la Torrea, Rodríguez Rodríguez, \& Martín Martínez (2020) resaltan en su estudio la necesidad de mayores datos sobre la forma en que el covid 19 afecta la gestación temprana. En embarazadas con COVID-19 debe vigilarse la restricción del crecimiento fetal, en vista de los cambios placentarios agudos y crónicos observados en otros estudios. "La infección por SARSCoV-2 se relaciona con el parto prematuro en el $47 \%$ de los casos notificados, aunque muchos de ellos lo son por interés materno". En cuanto al riesgo de transmisión horizontal (por gotas o por contacto), por lo general, por medio de un familiar próximo infectado, es igual que en la población general. Es recomendable que las mujeres embarazadas con infección confirmada por laboratorio y sean asintomáticas se autovigilen en su casa, con la finalidad de detectar las características clínicas de la evolución de la enfermedad durante al menos 14 día. Estas pacientes, y las que se recuperan de una forma leve de la enfermedad deben monitorearse mediante ecografías de crecimiento fetal bimestrales y evaluaciones Doppler, esto por causa del potencial riesgo de retraso de crecimiento intrauterino. (p. 4)

\section{Trabajo de parto y nacimiento}

En cuanto al trabajo de parto y nacimiento se recomienda:

- El modo de finalización del embarazo se definirá de acuerdo con el criterio obstétrico y con la condición de salud materna.

- Se recomienda el parto vía vaginal si la condición clínica de la madre lo permite. La evidencia actual no muestra ningún beneficio de la cesárea en embarazadas infectadas por COVID-19. Es importante evitar cesáreas injustificadas a fin de prevenir el nacimiento pretérmino y otras morbilidades en el recién nacido $(\mathrm{RN})$.

- Debe limitarse al mínimo necesario la presencia de personal de salud en la sala de partos. Se recomienda el uso de equipo de protección preventivo (EPP) que incluya botas, cofia, guantes, barbijo N95, camisolín hidrorrepelente y antiparras para medicx obstetra, lic.obstétricx y enfermerx. El resto del personal debe utilizar EPP con barbijo quirúrgico y camisolín común, y mantener una distancia interpersonal de al menos un me-

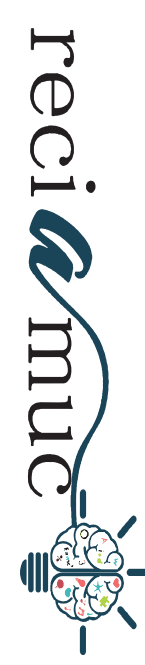


Definitivamente el contacto directo y temprano del recién nacido con la madre, así como la lactancia materna exclusiva ayudan en su desarrollo. La mujer con Covid 19, tras el parto, puede tener contacto con su hijo con la finalidad de favorecer el vínculo entre ambos y proporcionar al recién nacido de todos los beneficios que este contacto y alimentación materna le ofrecen, sin embargo, debe conocer y manejar toda la información necesaria con la finalidad de que sea esta la que tome la decisión de cuidar directamente al recién nacido o aislarlo temporalmente con la para protegerlo del coronavirus.

Por su parte, Serna García, Moreno Sánchez, González Cintora, \& Cruz Fernández (2020) realizaron una revisión bibliográfica de la evidencia disponible para la fecha con la finalidad de contrastar la información respecto al SARS-CoV-2 durante el proceso gestacional y sus efectos en la paciente obstétrica durante el parto, puerperio y en el recién nacido, encontrando los siguientes resultados:

Durante el puerperio inmediato algunos estudios recomiendan la adopción de medidas estrictas entre la madre infectada (asintomática o no) y su recién nacido, evitando piel con piel tras el parto y el clampaje tardío de cordón, y promoviendo el ingreso del recién nacido en habitación individual con medidas de aislamiento. Por el contrario, la OMS, el Ministerio de Sanidad y la Sociedad Española de Neonatología recomiendan que, en madres asintomáticas, ya sea con sospecha o confirmación de infección por COVID-19, y recién nacidos asintomáticos se puede valorar individualmente el clampaje tardío de cordón y contacto piel con piel tras el parto, así como el alojamiento conjunto de ambos en régimen de aislamiento de contacto y gotas. En estos casos se recomienda seguimiento clínico y monitorización básica del recién nacido. (p. 29)

La madre con Covid 19 debe observar una buena higiene respiratoria mientras da de mamar al recién nacido, usando mascarilla, si hay mascarillas disponibles, puede tener en brazos a su bebé, piel con piel; y compartir una habitación con este. Es necesario el lavado de manos antes y después de tocar al recién nacido y mantener todas las superficies limpias. En aquellos casos en que la madre esté demasiado enferma para amamantar al recién nacido, por causa del COVID-19 u otras complicaciones, esta deberá recibir apoyo para alimentarlo con leche materna de alguna manera posible, viable y aceptable para ella. Dentro de las opciones deben considerarse: la extracción de leche, la relactación y/o la leche de donante humana. (OPS, 2020)

Por otra parte, los Centros para la Prevención y el Control de Enfermedades de los Estados Unidos (2020), también reconocen que el ámbito ideal para el cuidado de un bebé sano recién nacido en término durante la hospitalización, después del nacimiento es dentro de la habitación de la madre, no obstante, se debería considerar la separación temporal entre el recién nacido y su madre con COVID-19 presunto o confirmado, con la finalidad de minimizar el riesgo de transmitir el virus a este. En cualquier caso, el equipo de atención médica debe comunicar a la madre los riesgos y beneficios de esta separación temporal y es la madre quien toma dicha decisión. Si la madre opta por esta separación temporal y desea amamantar, el procedimiento sería que esta deberá extraer su leche y hacer que un cuidador sano, con bajo riesgo de enfermarse gravemente por causa del COVID-19 alimente con biberón al recién nacido con la leche extraída. En el caso en que la madre con COVID-19 presunto o confirmado, decida la no separación del recién nacido en el hospital, debe tomar precauciones para evitar contagiarlo, entre las que se encuentran el lavado de las manos y usar una mascarilla al estar a menos de 6 pies de distancia del recién nacido. El recién nacido debe permanecer a 6 o más, pies de distancia de la madre, tanto tiempo como sea posi- 
ble, estas medidas pueden incluir el uso de barreras físicas, tales como la colocación del recién nacido en una incubadora. Una vez dadas de alta, en casa, las madres que escogieron la separación del recién nacido, deben seguir con el procedimiento para evitar el riesgo de contagiar al recién nacido, con la colaboración del cuidador, en caso contrario, de haber decidido cuidar ella misma a su bebe, igualmente debe seguir las medidas explicadas y practicadas durante la hospitalización, en el hogar.

La posición de la OMS (2020), ha sido más a favor del contacto de la madre con el recién nacido y de la lactancia materna. Reconoce que parte de un buen asesoramiento, ante la ansiedad de la madre o la familia sobre la COVID-19 es fundamental, y se debe responder a ellas con los siguientes mensajes:

- La lactancia materna y el contacto piel a piel reducen significativamente el riesgo de muerte en los neonatos y lactantes de corta edad y proporcionan beneficios a la salud y el desarrollo no solo inmediatos sino para toda la vida. Además, la lactancia materna reduce el riesgo de cáncer de mama y de ovario en la madre.

- Los neonatos y lactantes presentan un riesgo bajo de infección por el virus de la COVID-19. En los pocos casos de infección confirmada en niños de corta edad, la mayoría de las veces la enfermedad ha cursado con síntomas leves o sin síntomas.

- Los numerosos beneficios de la lactancia materna superan con creces los posibles riesgos de transmisión y enfermedad asociados a la COVID-19.

- No se ha detectado el virus activo en la leche materna de ninguna mujer con sospecha o confirmación de esta enfermedad, y no hay datos que demuestren que el virus pueda transmitirse al amamantar. (p. 4)

\section{Conclusiones}

Es mucho el camino por recorrer en la investigación del Covid 19 en todo el mundo. Los esfuerzos de organizaciones, gobiernos y particulares a nivel internacional, cada vez nos ponen a un paso más cerca de controlar la pandemia actual. Sin embargo, hasta los momentos es fundamental mantenerse actualizado con respecto a las evidencias científicas disponibles ya que son la base para el desarrollo de recomendaciones y estrategias en el manejo de la enfermedad.

Los diferentes protocolos y recomendaciones elaborados en todo el mundo acerca del covid 19 en el embarazo, parto y lactancia materna, han sido fundamentados en la escasa evidencia existente, dada la novedad de la enfermedad el virus no se ha podido estudiar en los primeros meses de gestación, así que es mucho lo que falta por conocer. Sin embargo, estudios en mujeres embarazadas infectadas con otros coronavirus como en SARS y MERS, han servido de apoyo ante los escases de información.

Las medidas preventivas para que las embarazadas sanas eviten el contagio son básicamente las medidas para la población en general. En cuanto a la atención durante el embarazo de la mujer con covid 19, debe existir una buena comunicación entre esta y el equipo de salud, a los fines de realizar un seguimiento de la condición de salud y establecer las estrategias que permitan prevenir la difusión del virus.

En cuanto al parto y el recién nacido, no existe evidencia científica que corrobore la trasmisión vertical. Las recomendaciones están dirigidas a la atención de la madre y del recién nacido, y la prevención del contagio del virus de la madre al hijo y hacia el personal de salud.

El personal de salud debe informar a la embarazada contagiada con Covid 19 de los beneficios y riesgos de la lactancia materna, con la finalidad de que sea esta la que tome la decisión de cuidar directamente al recién 
nacido o aislarlo temporalmente, en cuyo caso requerirá de la ayuda de un cuidador sano que no corra riesgo de enfermar severamente. La OMS. OPS y Unicef, dado sus múltiples beneficios y la falta de evidencia científica en cuanto a la transmisión vertical del virus o por medio de la leche materna, aunado al hecho de que estudios demuestran la poca probabilidad de que un recién nacido enferme gravemente de covid 19, apoyan la lactancia materna y el contacto directo de la madre con el recién nacido, con el uso correspondiente de las medidas preventivas para evitar el contagio.

\section{Bibliografía}

Abarzúa Camus, F. (2020). COVID-19 y Embarazo. Revista Chilena de Obstetricia y Ginecología, 85(2), 110-114. Recuperado el 25 de Julio de 2020, de https://scielo.conicyt.cl/pdf/rchog/v85n2/07177526-rchog-85-02-0110.pdf

Borre, D., Santacruz, J., González, J., Anichiarico, W., \& Rubio, J. (2020). Infección por SARS-CoV-2 en la paciente obstétrica: una perspectiva desde el cuidado crítico. Acta Colombiana de Cuidado Intensivo, 20(2), 98-107. Recuperado el 24 de Julio de 2020, de https://www.ncbi.nlm.nih.gov/pmc/ articles/PMC7158844/pdf/main.pdf

Centros para el Control y la Prevención de Enfermedades de los Estados Unidos. (25 de Junio de 2020). Centros para el Control y la Prevención de Enfermedades de los Estados Unidos. Recuperado el 04 de Julio de 2020, de https://espanol.cdc. gov/coronavirus/2019-ncov/need-extra-precautions/pregnancy-breastfeeding.html

González de la Torrea, H., Rodríguez Rodríguez, R., \& Martín Martínez, A. (04 de Mayo de 2020). Recomendaciones y manejo práctico de la gestante con COVID-19: scoping review. Enfermería Clínica, 7. Recuperado el 22 de Julio de 2020, de https:// www.ncbi.nlm.nih.gov/pmc/articles/PMC7231730/ $\mathrm{pdf} / \mathrm{main}$.pdf

Gutiérrez, M., Zelaya, S., Castellanos, E., \& Domínguez, R. (2020). Evidencia disponible sobre COVID-19 en mujeres embarazadas y lactancia materna. Ministerio de Salud del Gobierno del Salvador, Instituto Nacional de Salud. Recuperado el 24 de Julio de 2020, de http://docs.bvsalud.org/ biblioref/2020/04/1087778/evidencia-cientifica-sobre-embarazo-y-lactancia-covid-19-v2.pdf

Ministerio de Salud de Argentina. (2020). Covid 19. recomendaciones para la atención de embarazadas y recién nacidos en contexto de pandemia. Guía Clínica, Ministerio de Salud de Argentina, Instituto de Maternidad y Ginecología Nuestra Señora de las Mercedes, Tucumán, HZGA Blas L. Dubarry de la localidad de Mercedes (Provincia de Buenos Aires), Sanatorio de la Trinidad y Clínica y Maternidad Suizo Argentina, Buenos Aires. Recuperado el 21 de Julio de 2020, de http://www.msal.gob.ar/images/stories/bes/graficos/0000001839cnt-covid-19-recomendaciones-atencion-embarazadas-recien-nacidos.pdf

OMS. (12 de Mayo de 2020). Organización Mundial de la Salud. Recuperado el 05 de Julio de 2020, de https://www.who.int/docs/default-source/coronaviruse/breastfeeding-covid-who-faqs-es-12may2020.pdf?sfvrsn=f1fdf92c_8

OPS. (25 de Marzo de 2020). Organización Panamericana de la Salud. Recuperado el 02 de Julio de 2020, de https://www.paho.org/par/index.php?option $=$ com_content $\&$ view $=$ article $\& i d=2384$ : covid-19-el-embarazo-el-parto-y-la-lactancia-materna\&ltemid $=258$

OPS. (13 de Marzo de 2020). Organización Panamericana de la Salud. Recuperado el 02 de Julio de 2020, de https://www.paho.org/ venezuela/index.php?option=com_docman\&view $=$ download \&alias=150-covid -19 -embarazo-y-lactancia-mpps-ops-oms-y-unfpa\&category_ slug $=$ covid $-19 \&$ Itemid $=466$

Organización Panamericana de la Salud. (2020). Covid 19. Respuesta de la OPS/OMS. Organización Mundial de la Salud, Washintong D.C. Recuperado el 13 de Mayo de 2020, de file://C:/Users/ Usuario/Desktop/aymee/PAHO-reporte-operacional-04.05.20.pdf

Palacios Cruz, M., Santos, E., Velázquez, M., \& León, M. (26 de Febrero de 2020). COVID-19, una emergencia de salud pública mundial. Revista Clínica Española, 7. Recuperado el 25 de Julio de 202, de https://www.ncbi.nlm.nih.gov/pmc/articles/ PMC7102523/pdf/main.pdf

Pérez, J. A., Márquez, D., Lugo, C., Veroes, J., Cortes, R., Di Muro, J., . . A Araujo, K. (2020). Embarazada y Covid-19. Guía provisional. Sociedad de Obstetricia y Ginecología de Venezuela. Revista de Gonecología y Obstetricia de Venezuela, 80(1), S3 - S29. Recuperado el 04 de Julio de 220, de www.sogvzla.org.ve

Serna García, C., Moreno Sánchez, V., González Cintora, M., \& Cruz Fernández, J. M. (27 de Febrero de 2020). Enfermedad infecciosa por coronavirus (COVID-19) en lamujer embarazada y el neonato: impacto clínico y recomendaciones. Metas de 
Enfermería, 23(5), 22-32. Recuperado el 23 de Julio de 2020, de https://www.enfermeria21.com/ revistas/metas/articulo/81597/enfermedad-infecciosa-por-coronavirus-covid-19-en-la-mujer-embarazada-y-el-neonato-impacto-clinico-y-recomendaciones/

Unicef. (27 de Abril de 2020). Unicef Paraguay. Recuperado el 03 de Julio de 2020, de https:// www.unicef.org/paraguay/stories/embarazo-parto-y-lactancia-durante-la-pandemia-por-covid-19

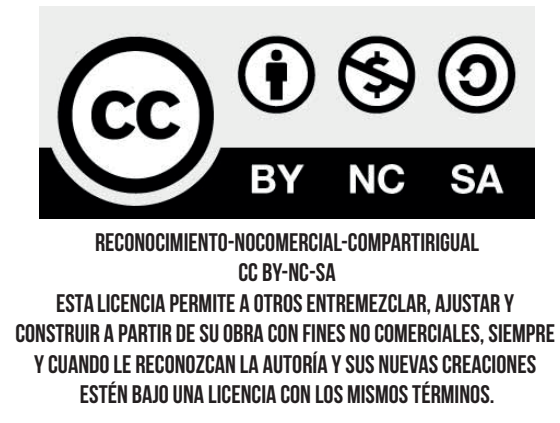

\section{CITAR ESTE ARTICULO:}

Merchan Villamar, J., Cedeño Cedeño, S., \& Rayo Caicedo, K. (2020). Covid 19, el embarazo, el parto y la lactancia materna. RECIMAUC, 4(3), 58-68. doi:10.26820/reciamuc/4.(3).julio.2020.58-68 